\title{
Ahmed glaucoma valves in refractory glaucoma: a 7-year audit
}

\author{
Peter K Wishart, Anshoo Choudhary, David Wong
}

St Paul's Eye Unit, Royal Liverpool and Broadgreen University Hospital, Liverpool, UK

\section{Correspondence to}

Dr Peter K Wishart, St Paul's Eye Unit, Royal Liverpool University Hospital, Prescot Street, Liverpool L7 8XP, UK; Peter.Wishart@rlbuht.nhs.uk

Synopsis: Ahmed glaucoma valve implantation is a relatively safe and effective procedure for the management of uncontrolled glaucoma. Steps designed to reduce the incidence of serious postoperative complications (including hypotony and tube erosion) are described.

Accepted 15 November 2009 Published Online First 3 December 2009

\begin{abstract}
Purpose To present the long-term results of Ahmed glaucoma valve (AGV) implantation.

Methods Consecutive case series of 94 eyes with AGV implantation over 7 years. Temporary tube ligation with C3F8 gas fill was used in high-risk eyes (group GqL) and compared with standard implantation in both phakic (group A) and pseudophakic/aphakic eyes (group B). Success was intraocular pressure (IOP) of $6 \mathrm{~mm} \mathrm{Hg}$ or greater and $21 \mathrm{~mm} \mathrm{Hg}$ or less and/or IOP reduction of $20 \%$ or greater.
\end{abstract}

Results Average follow-up was $28.9 \pm 20.3$ months. The mean preoperative IOP changed from $30.8 \pm 8.2$ to $19.7 \pm 7.6 \mathrm{~mm} \mathrm{Hg}$ and mean preoperative medications changed from $3.3 \pm 1.2$ to $1.2 \pm 1.1$ at the final visit. Cumulative probability of survival at 1 and 4 years was $89.1 \%$ and $72.9 \%$. There was no statistically significant difference in success between the three groups, but complications due to postoperative hypotony (six eyes) only occurred in group B. Other complications were corneal decompensation (three eyes), tube erosion (six eyes) and aqueous misdirection (four eyes).

Conclusions AGV implantation offered good long-term IOP control with a success rate of $78.7 \%$. The authors recommend C3F8 gas fill and temporary tube ligation in eyes at high risk of postoperative hypotony and the use of donor sclera or human pericardial patch to prevent tube erosion.

Glaucoma tube implants (aqueous shunts) are used for the surgical treatment of uncontrolled intraocular pressure (IOP) in eyes with refractory glaucoma, and reported success rates are between 60 and $82 \%$ at 2 years, ${ }^{1-5}$ with a reported $10 \%$ per year failure rate. $^{6}$ The most serious immediate complications of aqueous shunts are those related to postoperative hypotony, including shallow and flat anterior chambers, choroidal detachments and suprachoroidal haemorrhage (SCH).$^{7-9}$ Erosion of the tube through the conjunctiva is a potential hazard of aqueous shunts and may lead to endophthalmitis. ${ }^{10}$ Corneal endothelial failure (CEF) has been described as the principal long-term complication. ${ }^{6}$

To avoid postoperative hypotony non-valved shunts are now implanted with a temporary ligature of the tube. The Ahmed glaucoma valve (AGV; Rancho Cucamonga, California, USA) has a silicone elastomer membrane held in a polypropylene or silicone body forming a non-obstructive valve that should prevent excessive aqueous drainage and anterior chamber collapse. However, postoperative hypotony has been reported in up to $29 \%$ of cases $^{1} 4^{511-13}$ of AGV implantation, causing flat anterior chambers in up to $10 \%$ of eyes and SCH in up to $5 \%$ of eyes. ${ }^{12} 1113-15$
We report an audit of consecutive cases of AGV implanted from 2002 to 2008 by one surgical team, highlighting our attempts to reduce the incidence of serious complications such as postoperative hypotony and tube erosion. Sudden hypotony following surgical decompression is reported to be the precipitating factor responsible for the occurrence of $\mathrm{SCH}$ with aphakia, pseudophakia and previous vitrectomy identified as the major risk factors for SCH. ${ }^{16-18}$ From September 2004 , we attempted to avoid hypotony in eyes with these risk factors by using anterior chamber C3F8 gas fill coupled with polyglactin (Vicryl, Ethicon) suture ligation as described by Franks and Hitchings ${ }^{19}$ for use in non-valved implants. To prevent conjuctival tube erosion we used a scleral patch graft, ${ }^{20}$ a scleral rotation flap ${ }^{21}$ or a pericardial patch graft. ${ }^{22}$ As this gas and ligature $(G \& L)$ technique might carry the risk of inducing a postoperative IOP spike or prolonging the 'hypertensive phase' commonly seen with AGV implantation, ${ }^{2} 1114$ we compared the postoperative pressure profiles of our G\&L eyes with those of glaucomatous eyes undergoing standard AGV implantation in our unit during the same time period.

\section{PATIENTS AND METHODS \\ Patient selection}

The indication for AGV implantation was the presence of glaucoma with medically uncontrolled IOP and the presence of factors that would make filtering surgery unlikely to be successful, such as uveitis, previous failed filtering surgery or aphakia. All eyes undergoing AGV implantation from January 2002 to July 2008 were included in this consecutive case series. The majority of the implants were the S-2 single plate model. From January 2008 onwards we implanted only the FP-7 model (single plate silicone body). Surgery was performed by one of the authors (PKW) in all but six eyes, in which surgery was under the supervision of PKW.

\section{Data collection}

For each patient we documented the age, gender, race, glaucoma diagnosis, total number of operations before the AGV insertion, presenting IOP, preoperative IOP and visual acuity, gonioscopy and corneal thickness measured by ultrasonic pachymetry ('Pachmate'; DGH Technologies, Exton, Pennsylvania, USA). Full ophthalmic examination with visual acuity, Goldmann applanation tonometry and fundus examination were performed at all visits. The mean number of medications was calculated by the addition of each medication as one unit, with fixed combinations scored as two and systemic acetazolamide-Diamox SR (Goldshield Pharmaceuticals, Croydon, UK), dose $250 \mathrm{mg}$ twice a day-also scored as two units. Postoperatively the IOP and visual acuity were noted at 
day 1 , day 7 , month 1 , month 2 and thereafter at 3-6-monthly intervals.

\section{Technique}

Following a case of SCH after AGV implantation in an aphakic eye in September 2004, we modified our technique of AGV implantation such that all high-risk eyes undergoing AGV implantation had 14\% perfluoropropane (C3F8) gas injection into the anterior chamber by means of a paracentesis and ligation of the tube with a 5 ' $O$ ' Vicryl suture. Such cases are reported as our G\&L group. Eyes having standard implantation without gas or ligature are reported as standard group A (phakic eyes) and standard group B (aphakic/pseudophakic eyes). On implanting an AGV it is necessary first to prime the valve with balance salt solution (Alcon, Fort Worth, Texas, USA), which creates a small drainage hole at the posterior edge of the elastomer membrane. To prevent injected C3F8 gas escaping up the tube and through this hole, temporary occlusion of the tube was provided by a 5 ' $O$ ' Vicryl ligature. The ligature was tied with three throws of the suture to achieve a compression rather than occlusion of the tube and pulled tight enough to prevent the escape of gas from the anterior chambers up the tube. The high surface tension of a C3 F8 gas bubble should prevent anterior chamber collapse in the event of excess aqueous leak round the tube or the sudden development of choroidal detachments. Tube implantation in all cases was by means of a '23'-gauge needle track $2 \mathrm{~mm}$ posterior to the limbus through full thickness scleral tissue into the anterior chamber to achieve a water-tight fit. To cover the tube, we used either an autologous scleral rotation flap (figure 1), ${ }^{21}$ or a donor scleral or pericardial patch. ${ }^{20}$ We initially used bovine pericardium: Tutopatch (Tutogen GMBh, Neunkirchen am Brand, Germany), but after observing overlying conjunctival melt in some cases we changed to human donor pericardium: Tutoplast (Tutogen GMBh). The conjunctiva was closed with interrupted 8 ' $\mathrm{O}$ ' or 10 ' $\mathrm{O}$ ' Vicryl sutures. No antimetabolites were used in this study. Postoperative topical steroids, Pred Forte (Allergan, Irvine, California, USA) were given four times a day for 1-2 months and atropine drops twice a day for 2 weeks.

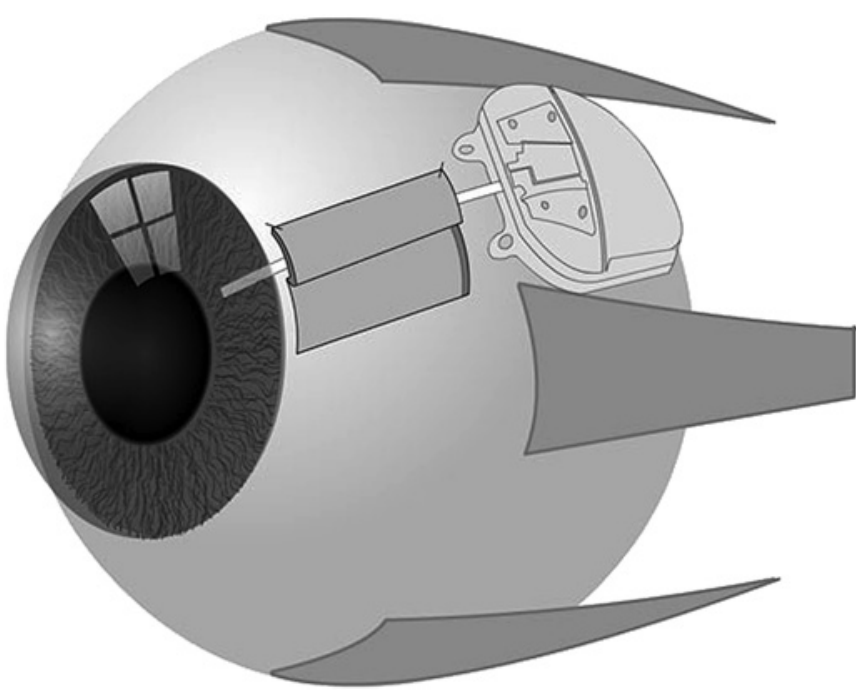

Figure 1 Silicone tube of Ahmed glaucoma valve is covered by a scleral rotation flap.

\section{Outcome measures}

Success was defined as in the Tube Versus Trabeculectomy Study $^{723}$ : IOP $6 \mathrm{~mm} \mathrm{Hg}$ or greater and $21 \mathrm{~mm} \mathrm{Hg}$ or less with or without medication and/or IOP reduction of $20 \%$ or greater relative to preoperative values. Failure was defined as IOP greater than $21 \mathrm{~mm} \mathrm{Hg}$ or not reduced by $20 \%$ below baseline on two consecutive follow-up visits after 3 months, IOP of $5 \mathrm{~mm} \mathrm{Hg}$ or less on two consecutive follow-up visits after 3 months, reoperation for glaucoma, or loss of light perception vision. Eyes that had not failed and were not on supplemental medical therapy were considered complete successes. Eyes that had not failed but required supplemental medical therapy were defined as qualified successes.

\section{Statistical analysis}

Statistical analysis was performed using the SPSS 16 software for Windows. Descriptive statistics were employed to summarise demographics and outcome characteristics of the groups. Student's t test was used to determine the significance of any differences in the continuous variables within each group. The Wilcoxon signed rank test was used to compare the pre and postoperative antiglaucoma medication scores. The one-way analysis of variance was used to compare means of the three groups and post hoc tests were used for comparisons between groups. A p value of less than 0.05 was taken as statistically significant. The cumulative probability of success was derived using the Kaplan-Meier survival curve and the log-rank test was used to compare survival between groups. The time to failure was defined as the time from AGV implantation to re-operation for glaucoma or the first of the two consecutive visits after 3 months when the patient had hypotony or uncontrolled IOP.

\section{RESULTS}

Ninety-four eyes of 83 patients underwent AGV implantation with a mean follow-up of $28.9 \pm 20.3$ months (range $2-84$ ). These included 51 high-risk eyes that underwent AGV with gas fill and ligature (G\&L group; 50 aphakic/pseudophakic and one myopic phakic) and 43 eyes that underwent standard AGV implantation, comprising 28 phakic (standard group A) and 15 pseudophakic/ aphakic (standard group B) eyes. Patient demographics and preoperative characteristics are detailed in table 1.

The G\&L group and standard group B had a significantly higher mean age ( 66.5 and 65.6 years vs 50.5 years) and number of previous operations (2.4 and 2.1 vs 0.9 ) compared with the standard group $A$ $(p=0.001$ and 0.000 , table 2 , figure 2$)$. There was no significant difference between the groups in respect of the presenting IOP, preoperative IOP and number of medications ( $p>0.05)$.

The mean preoperative and postoperative IOP, antiglaucoma medication, outcome and complications are detailed in table 2. Postoperative IOP control with time is shown in figure 2. The change in IOP was statistically significant at all times postoperatively in all groups. The mean IOP at day 1 and day 7 was significantly higher in the G\&L group compared with the standard $A$ and $B$ groups $(p=0.000$ and 0.006$)$. There was no significant difference in IOP at days 1 and 7 between standard groups A and B. On the first postoperative day, eight eyes in the G\&L group had IOP greater than $30 \mathrm{~mm} \mathrm{Hg}$ (mean $38 \mathrm{~mm} \mathrm{Hg}$, range 32-45 mm $\mathrm{Hg}$ ), which was relieved by tapping the gas bubble by needle pressure on the site of the paracentesis. There was no significant difference in the final IOP between the groups $(\mathrm{p}=0.56)$. The mean number of medications reduced significantly in all groups (table 2 , $p<0.001)$ and there was no significant difference in the postoperative medication scores of the three groups $(p=0.4)$. At final 
Table 1 Patient demographics and characteristics of study population

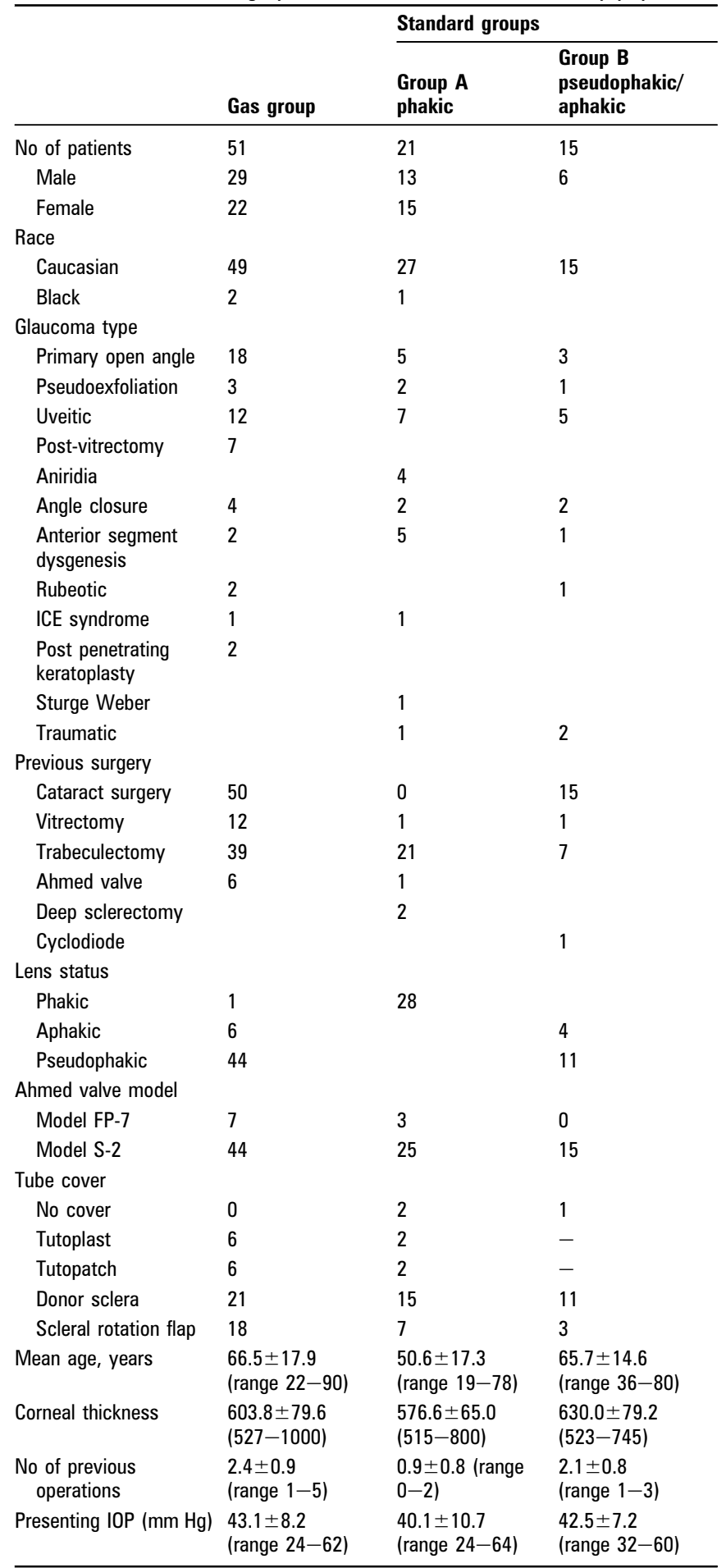

ICE, iridocorneal endothelial; IOP, intraocular pressure.

follow-up success was achieved in 75\% eyes in the G\&L group, $82.1 \%$ in standard group $\mathrm{A}$ and $73.4 \%$ in standard group $\mathrm{B}$. Complete success was achieved in $30.8 \%$ eyes in the G\&L group, $39.2 \%$ in standard group A and $13.3 \%$ in standard group B. Kaplan-Meier survival analysis is detailed in figure 3 . The cumulative probability of maintaining an IOP of $6 \mathrm{mmHg}$ or greater and $21 \mathrm{mmHg}$ or less and/or a $20 \%$ or greater drop in IOP for the G\&L group, standard group A and standard group B was $87.9 \%, 92.4 \%$ and $86.7 \%$ at 1 year and $62.9 \%, 71.5 \%$ and $86.7 \%$ at 4 years, with a mean survival time of 38.7 months, 66.6 months and 62.7 months. There was no statistically significant difference in the survival between groups $(p=0.19)$.

Complications are summarised in table 2. CEF directly attributable to AGV implantation occurred in only one eye. This eye was in the G\&L group and followed the development of aqueous misdirection with a flat anterior chamber after AGV implantation. CEF worsened after AGV implantation in two eyes with previous intraocular surgery. Late CEF was seen in three other eyes with pre-existing corneal damage-two traumatic aphakic eyes, one iridocorneal endothelial syndrome eye. There was one case of SCH occurring in a 73-year-old aphakic eye with previous vitrectomy that underwent standard AGV implantation. Visual acuity was reduced to perception of light but after drainage of the haemorrhage and vitrectomy with injection of heavy oil, the vision recovered to 6/9. Aqueous misdirection occurred in four pseudophakic eyes after AGV implantation. Zonulo-hyaloido-vitrectomy ${ }^{24}$ was effective in correcting the aqueous misdirection in all cases. Three of the four cases occurred in eyes with previous acute angle closure glaucoma. Three eyes with advanced visual field loss had a reduction of vision to levels of hand movements by final follow-up.

\section{DISCUSSION}

The purpose of this report is to share our experience of the success and hazards attendant on AGV implantation and to describe our attempts to improve the safety of AGV implantation. Sudden postoperative hypotony following tube implantation can lead to serious complications: shallow/flat anterior chambers, the development of choroidal effusions or SCH. SCH is associated with sudden lowering of IOP with aphakic, pseudophakic and vitrectomised glaucomatous eyes especially at risk of this complication following tube implant surgery, ${ }^{16-18}$ and SCH can follow even relatively minor surgical procedures in glaucomatous eyes. ${ }^{25} 26$ Shallow or flat anterior chambers in pseuodophakic eyes are a serious complication as this may permit the tube or the intraocular lens implant to touch the corneal endothelium leading to late CEF.

Complications of hypotony do still occur despite tube ligation of non-valved aqueous shunts, with reports of choroidal effusion in $16 \%$, shallow or flat anterior chambers in $11 \%$ and SCH in $2 \% .^{79}$ Following AGV implantation, despite the presence of a valve, a similar rate of these complications still occurs. ${ }^{2} 91415$ $\mathrm{Kee}^{13}$ described the use of a ligature technique with AGV reducing postoperative hypotony from $25 \%$ to $6 \%$, but we could not find any reports of the use of C3F8 with the AGV.

The technique of $14 \%$ C3F8 gas fill and ligature in our study was effective in preventing early hypotony and shallow/flat anterior chambers in our G\&L group. All our serious complications related to a sudden reduction of IOP postoperatively were seen in the ahakic/pseudophakic eyes with standard implantation in group B. Although eight eyes developed IOP greater than $30 \mathrm{~mm} \mathrm{Hg}$ on day 1 , this IOP was on no glaucoma medication. The mean IOP in the G\&L group on the first postoperative day was $19.4 \mathrm{~mm} \mathrm{Hg}$, which is similar to that reported for non-valved Glaucoma Drainage Devices (GDD) $)^{79}$ or following cataract surgery ${ }^{27}$ or following cyclodiode laser ablation. ${ }^{28} 29$

Four cases of aqueous misdirection occurred in the G\&L group in pseudophakic eyes, three of which had had previous acute angle closure glaucoma. In the fourth eye the aqueous misdirection occurred peroperatively before C3F8 injection as it was noted that there was sudden shallowing of the anterior chamber and the anterior chamber could not be deepened with a C3F8 gas fill, the anterior chamber only retaining a very small amount of gas. 
Table 2 Results

\begin{tabular}{|c|c|c|c|}
\hline & \multirow[b]{2}{*}{$\begin{array}{l}\text { Gas and ligature } \\
\text { group }\end{array}$} & \multicolumn{2}{|l|}{ Standard groups } \\
\hline & & $\begin{array}{l}\text { Group A } \\
\text { phakic }\end{array}$ & $\begin{array}{l}\text { Group B pseudophakic/ } \\
\text { aphakic }\end{array}$ \\
\hline Mean follow-up, months & $23.3 \pm 13.9$ (range $2-48$ ) & $28.5 \pm 22.1$ (range $6-84$ ) & $49.8 \pm 22.7$ (range $2-72$ ) \\
\hline \multicolumn{4}{|l|}{ Mean IOP } \\
\hline Preoperative & $\begin{array}{l}29.8 \pm 7.6 \mathrm{~mm} \mathrm{Hg} \\
\text { (range } 16-50 \text { ) }\end{array}$ & $\begin{array}{l}31.4 \pm 9.8 \mathrm{~mm} \mathrm{Hg} \\
\text { (range } 16-56 \text { ) }\end{array}$ & $\begin{array}{l}33.3 \pm 6.5 \mathrm{~mm} \mathrm{Hg} \\
\text { (range } 25-45 \text { ) }\end{array}$ \\
\hline $\begin{array}{l}\text { Postoperative } \\
\text { (final visit) }\end{array}$ & $\begin{array}{l}20.0 \pm 7.5 \mathrm{~mm} \mathrm{Hg} \\
\text { (range } 10-50 \text { ) }\end{array}$ & $\begin{array}{l}18.9 \pm 6.2 \mathrm{~mm} \mathrm{Hg} \\
\text { (range } 7-34 \text { ) }\end{array}$ & $\begin{array}{l}20.5 \pm 10.2 \mathrm{~mm} \mathrm{Hg} \\
\text { (range } 12-46 \text { ) }\end{array}$ \\
\hline Percentage change & $\begin{array}{l}30.8 \pm 22.6 \% \\
\text { (range }-42.9 \text { to } 75.5 \text { ) }\end{array}$ & $\begin{array}{l}34.5 \pm 24.2 \% \\
\text { (range }-6.7 \text { to } 73.1 \text { ) }\end{array}$ & $\begin{array}{l}36.2 \pm 33.6 \% \\
\text { (range }-43.8 \text { to } 69 \text { ) }\end{array}$ \\
\hline \multicolumn{4}{|l|}{ Outcome (eyes) } \\
\hline Success & $38(75 \%)$ & $23(82.1 \%)$ & $13(86.7 \%)$ \\
\hline Complete & $16(30.8 \%)$ & $11(39.2 \%)$ & $2(13.3 \%)$ \\
\hline Qualified & $22(44.2 \%)$ & $12(42.8 \%)$ & $11(73.4 \%)$ \\
\hline Failure & $12(25 \%)$ & $5(17.9 \%)$ & $2(13.3 \%)$ \\
\hline \multicolumn{4}{|l|}{ Medication } \\
\hline Preoperative score & $3.2 \pm 1.1$ (range $1-5$ ) & $3.3 \pm 1.6($ range $0-7)$ & $3.5 \pm 0.9$ (range $2-5)$ \\
\hline Postoperative score (topical) & $1.3 \pm 1.2$ (range $0-4$ ) & $1.0 \pm 0.9$ (range $0-3$ ) & $1.3 \pm 0.8$ (range $0-3$ ) \\
\hline \multicolumn{4}{|l|}{ Complications (eyes) } \\
\hline \multicolumn{4}{|l|}{ Early postoperative } \\
\hline IOP $>30 \mathrm{~mm} \mathrm{Hg}$ day 1 & 8 (range $32-45 \mathrm{~mm} \mathrm{Hg}$ ) & 0 & 2 \\
\hline $\mathrm{SCH}$ & & & 1 \\
\hline Choroidal detachment & & & 5 \\
\hline Aqueous misdirection & 4 & 1 & \\
\hline Iris/vitreous in tube & 2 & & \\
\hline Hyphaema/vitreous haemorrhage & 2 & & \\
\hline \multicolumn{4}{|l|}{ Late postoperative } \\
\hline \multicolumn{4}{|l|}{ Tube erosion } \\
\hline No cover & - & $1 / 2$ & $1 / 1$ \\
\hline Tutoplast & $0 / 6$ & $0 / 2$ & - \\
\hline Tutopatch & $1 / 6$ & $2 / 2$ & - \\
\hline Donor sclera & $0 / 21$ & $0 / 15$ & $0 / 11$ \\
\hline Scleral rotation flap & $3 / 18$ & $0 / 7$ & $0 / 3$ \\
\hline Corneal decompensation & 1 & 1 & 1 \\
\hline Retinal detachment & 2 & & \\
\hline Mild diplopia & 4 & 2 & 1 \\
\hline Tube repositioning & & & 3 \\
\hline
\end{tabular}

$\mathrm{IOP}$, intraocular pressure; $\mathrm{SCH}$, suprachoroidal haemorrhage.

Figure 2 Change in intraocular pressure (IOP) with time. Mean preoperative IOP changed from $29.8 \pm 7.6$ to $20 \pm 7.5 \mathrm{~mm} \mathrm{Hg}$ (gas and ligature group), $31.4 \pm 9.8$ to $18.9 \pm 6.2 \mathrm{~mm} \mathrm{Hg}$ (standard phakic group) and $33.3 \pm 6.5$ to $20.5 \pm 10.2 \mathrm{~mm} \mathrm{Hg}$ (standard pseudophakic/aphakic group) at final visit, a mean change of 30.8 , 34.5 and $36.2 \%$. The change in IOP was statistically significant at all times postoperatively $(\mathrm{p}<0.05)$.

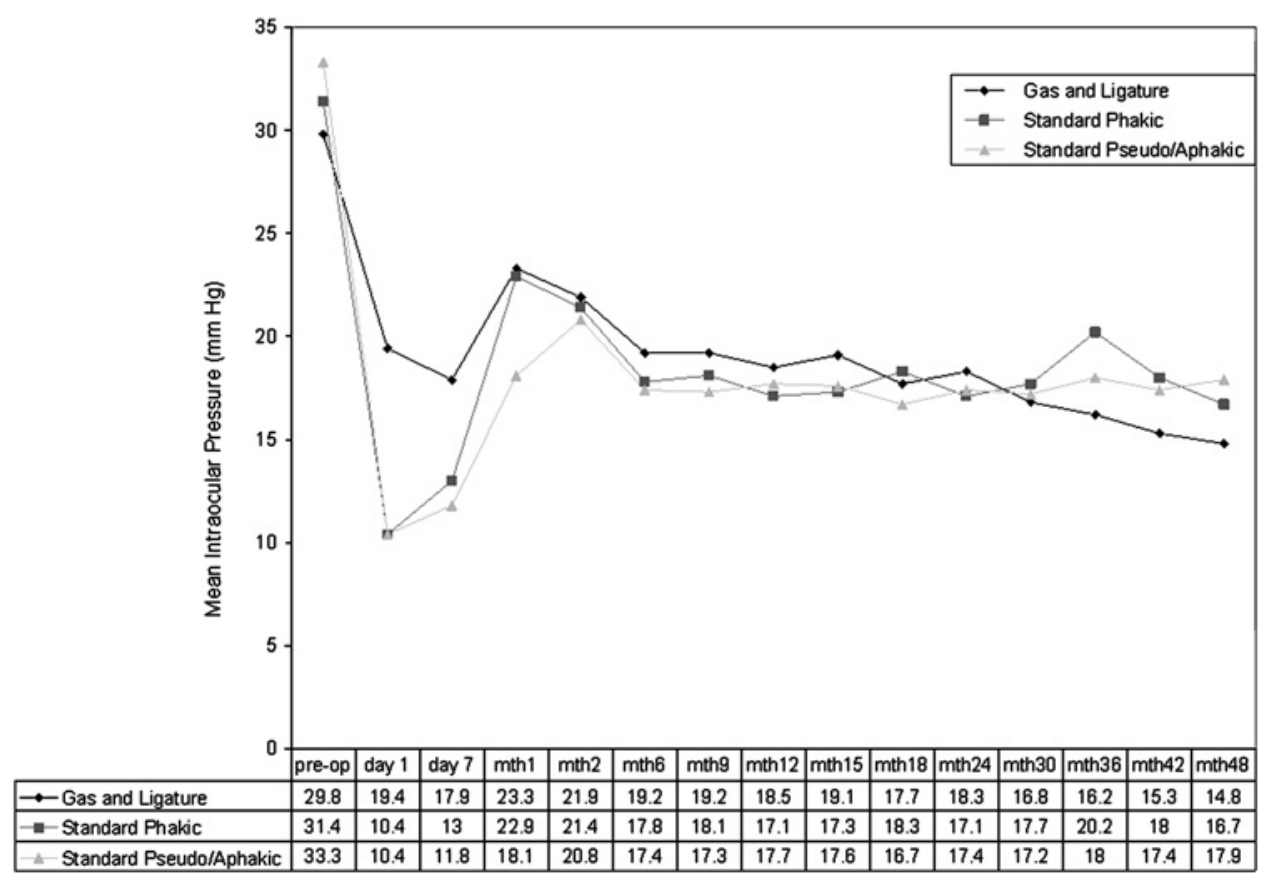


Figure 3 Kaplan-Meier survival curve for the groups. Kaplan-Meier survival analysis showed a cumulative probability of maintaining an intraocular pressure (IOP) of $6 \mathrm{~mm} \mathrm{Hg}$ or greater and $21 \mathrm{~mm} \mathrm{Hg}$ or less and/or an IOP drop of $20 \%$ or greater for the gas and ligature group (G\&L), standard phakic group and standard aphakic/ pseudophakic group to be $87.9 \%, 92.4 \%$ and $86.7 \%$ at 1 year and $62.9 \%, 71.5 \%$ and $86.7 \%$ at 4 years, with a mean survival time of 38.7 months, 66.6 months 62.7 months, respectively. There was no statistically significant difference in the survival between groups $(p=0.19)$.

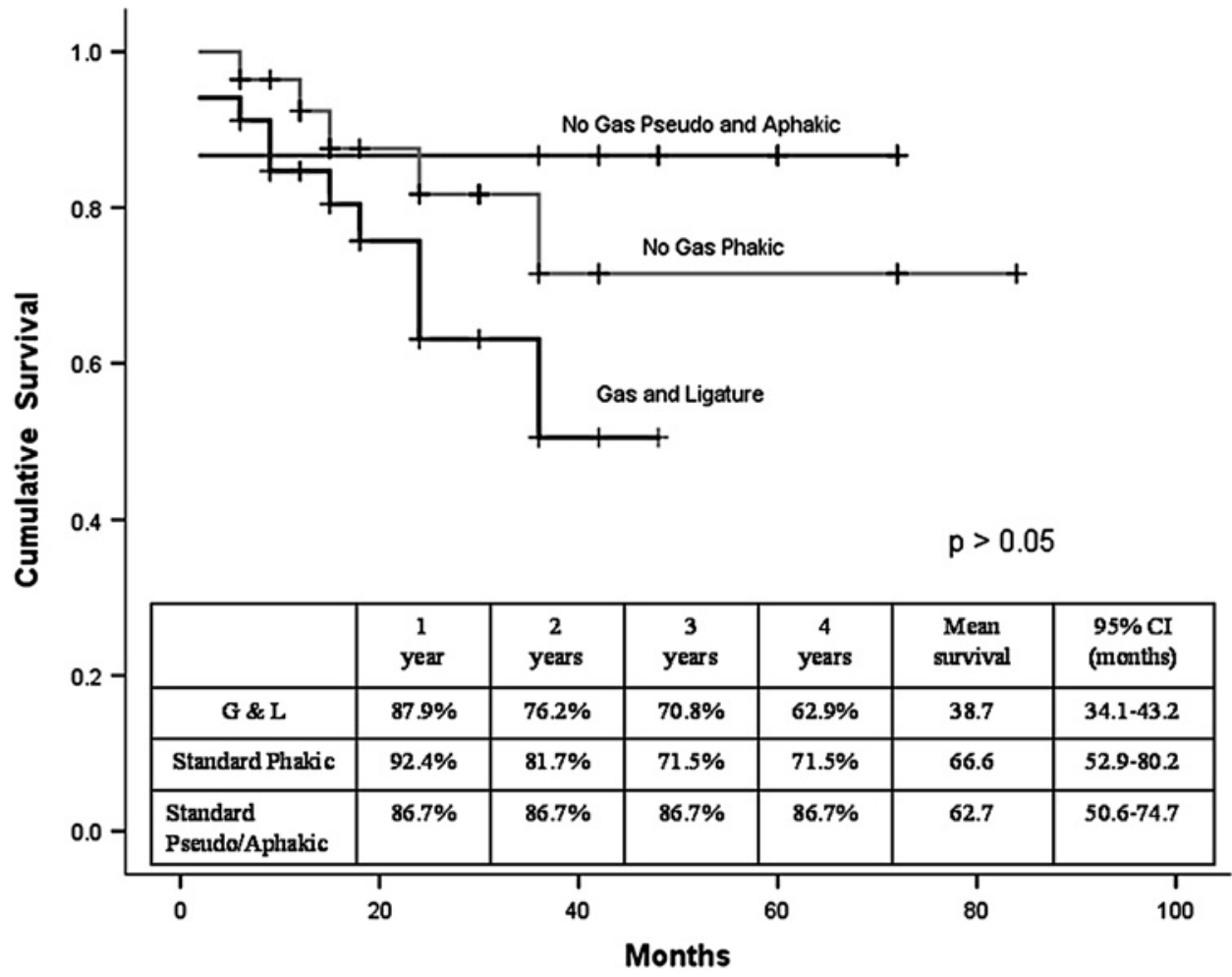

Therefore, we do not feel gas contributed to the development of aqueous misdirection, which has been observed in up to $3 \%$ of other studies of tube implants. ${ }^{2} 7111415$ All cases responded to zonulo-hyaloidectomy with anterior vitrectomy through a peripheral iridectomy as described by Lois et al. ${ }^{24}$

We had a low incidence of new corneal failure (one eye) developing postoperatively in our series and we suspect this may be related to our low incidence of shallow/flat anterior chambers and hypotony, which reduced the risk of tube/corneal touch. The five other eyes with CEF all had significant preoperative corneal disease.

The AGV 'hypertensive phase' is an elevation in IOP occurring within the first 3 months postoperatively, reported to occur in between $48.5 \%$ and $82 \%$ of eyes undergoing AGV implantation, ${ }^{2} 111415$ and to resolve in approximately $30 \%$ of cases. ${ }^{14}$ On days 1 and 7 the mean IOP was higher in the G\&L group than in the standard groups A and B (figure 2). After day 7 the IOP in the three groups was very similar during follow-up. In all groups the IOP peaked at 1 month postoperatively, presumably indicating the peak of the AGV hypertensive phase. This finding would seem to indicate that the only effect on AGV function of gas and ligature was to elevate the mean IOP temporarily in the first postoperative week. There was no statistically significant difference between the surgical success rates of AGV implantation between our G\&L and standard groups $\mathrm{A}$ and $\mathrm{B}$.

Other studies of AGV implantation report success rates at 12 months of $70.5 \%$ to $83 \%$, achieving mean IOP of $16.4 \mathrm{~mm} \mathrm{Hg}$ to $18.3 \mathrm{~mm} \mathrm{Hg}$ on a mean of 1.3 medications, which are similar to our success rates but with a higher rate of postoperative hypotony than ours. ${ }^{9} 111314$

\section{Preventing conjunctival tube erosion}

Without a patch graft or scleral flap to cover the tube, there can be a high rate of tube erosion ${ }^{10}$ predisposing the eye to the development of infectious endophthalmitis. ${ }^{30} 31 \mathrm{~A}$ rate of tube exposure of up to $7 \%$ following donor scleral patch grafts has been reported, ${ }^{11} 1532$ and although donor sclera for a patch graft was successful in preventing erosion in our cases, we used the scleral rotation flap ${ }^{21}$ method of covering the tube as this avoids the potential transmission of infection from donor tissue. ${ }^{33}$ However, we noted three erosions out of our 28 scleral rotation flap cases and therefore abandoned this technique latterly and used dried stored pericardium as a patch cover. Tube erosion has previously been reported in up to $2.6 \%$ of cases in which human pericardium was used, ${ }^{22} 3435$ and so we initially used bovine pericardium (Tutopatch) to prevent erosion as it is twice as thick. However, with Tutopatch, a severe inflammation of the conjunctiva overlying the tube developed in the first postoperative month in $30 \%$ of cases. We therefore abandoned Tutopatch and have since used human pericardium (Tutoplast) as the tube cover with no inflammation or erosions to date.

\section{CONCLUSIONS}

In complex eyes unlikely to respond to conventional filtering procedures, AGV provides a good long-term rate of success with a low rate of complications. We had no cases of endophthalmitis and no cases of persistent hypotony over our 7-year study.

C3F8 gas and temporary Vicryl ligature is a useful technique for the prevention of postoperative hypotony when implanting AGV in high-risk eyes, for example, previous vitrectomy, aphakia or high myopia.

Donor sclera and human pericardium (Tutoplast) appear to be as effective as patch grafts to prevent conjunctival tube erosion.

CEF was an unusual complication of AGV in our study, and we feel that the avoidance of hypotony may be an important factor by preventing shallow or flat anterior chambers and subsequent tube or lens/corneal endothelial touch.

Competing interests None.

Provenance and peer review Not commissioned; externally peer reviewed.

\section{REFERENCES}

1. Coleman AL, Hill R, Wilson MR, et al. Initial clinical experience with the Ahmed glaucoma valve implant. Am J Ophthalmol 1995;120:23-31.

2. Ishida K, Netland PA, Costa VP, et al. Comparison of polypropylene and silicone Ahmed glaucoma valves. Ophthalmology 2006;113:1320-6. 
3. Ozdal PC, Vianna RN, Deschenes J. Ahmed valve implantation in glaucoma secondary to chronic uveitis. Eye 2006;20:178-83.

4. Huang MC, Netland PA, Coleman AL, et al. Intermediate-term clinical experience with the Ahmed glaucoma valve implant. Am J Ophthalmol 1999;127:27-33.

5. Souza C, Tran DH, Loman J, et al. Long-term outcomes of Ahmed glaucoma valve implantation in refractory glaucomas. Am J Ophthalmol 2007:144:893-900.

6. Minckler DS, Francis BA, Hodapp EA, et al. Aqueous shunts in glaucoma: a report by the American Academy of Ophthalmology. Ophthalmology 2008;115:1089-98.

7. Gedde SJ, Herndon LW, Brandt JD, et al. Surgical complications in the Tube Versus Trabeculectomy Study during the first year of follow-up. Am J Ophthalmol 2007;143:23-31.

8. Heuer DK, Lloyd MA, Abrams DA, et al. Which is better? One or two? A randomized clinical trial of single-plate versus double-plate Molteno implantation for glaucomas in aphakia and pseudophakia. Ophthalmology 1992;99:1512-19.

9. Tsai JC, Johnson CC, Kammer JA, et al. The Ahmed shunt versus the Baerveldt shunt for refractory glaucoma II: longer-term outcomes from a single surgeon. Ophthalmology 2006;113:913-17.

10. Woodcock MG, Richards JC, Murray AD. The last 11 years of Molteno implantation at the University of Cape Town. Refining our indications and surgical technique. Eye 2008;22:18-25.

11. Ayyala RS, Zurakowski D, Smith JA, et al. A clinical study of the Ahmed glaucoma valve implant in advanced glaucoma. Ophthalmology 1998;105:1968-76.

12. Coleman AL, Mondino BJ, Wilson MR, et al. Clinical experience with the Ahmed glaucoma valve implant in eyes with prior or concurrent penetrating keratoplasties. Am J Ophthalmol 1997;123:54-61.

13. Kee C. Prevention of early postoperative hypotony by partial ligation of silicone tube in Ahmed glaucoma valve implantation. J Glaucoma 2001;10:466-9.

14. Nouri-Mahdavi K, Caprioli J. Evaluation of the hypertensive phase after insertion of the Ahmed glaucoma valve. Am J Ophthalmol 2003;136:1001-8.

15. Susanna R Jr. Partial Tenon's capsule resection with adjunctive mitomycin $C$ in Ahmed glaucoma valve implant surgery. Br J Ophthalmol 2003;87:994-8.

16. Canning CR, Lavin M, McCartney AC, et al. Delayed suprachoroidal haemorrhage after glaucoma operations. Eye 1989;3:327-31.

17. Cantor LB, Katz LJ, Spaeth GL. Complications of surgery in glaucoma. Suprachoroidal expulsive hemorrhage in glaucoma patients undergoing intraocular surgery. Ophthalmology 1985;92:1266-70.

18. Ruderman JM, Harbin TS Jr, Campbell DG. Postoperative suprachoroidal hemorrhage following filtration procedures. Arch Ophthalmol 1986;104:201-5.

19. Franks WA, Hitchings RA. Injection of perfluoropropane gas to prevent hypotony in eyes undergoing tube implant surgery. Ophthalmology 1990;97:899-903.
20. Freedman J. Scleral patch grafts with Molteno setons. Ophthalmic Surg 1987; 18:532-4.

21. Aslanides IM, Spaeth GL, Schmidt CM, et al. Autologous patch graft in tube shunt surgery. J Glaucoma 1999;8:306-9.

22. Raviv T, Greenfield DS, Liebmann JM, et al. Pericardial patch grafts in glaucoma implant surgery. J Glaucoma 1998;7:27-32.

23. Gedde SJ, Schiffman JC, Feuer WJ, et al. Treatment outcomes in the tube versus trabeculectomy study after one year of follow-up. Am J Ophthalmol 2007;143:9-22.

24. Lois $\mathbf{N}$, Wong D, Groenewald C. New surgical approach in the management of pseudophakic malignant glaucoma. Ophthalmology 2001;108:780-3.

25. Sathyan $\mathbf{P}$, Singh G, Eong KG, et al. Suprachoroidal hemorrhage following removal of releasable suture after combined phacoemulsification-trabeculectomy. J Cataract Refract Surg 2007;33:1104-5.

26. Syam PP, Hussain B, Anand N. Delayed suprachoroidal hemorrhage after needle revision of trabeculectomy bleb in a patient with hairy cell leukemia. Am J Ophthalmol 2003;136:1155-7.

27. Barak A, Desatnik H, Ma-Naim T, et al. Early postoperative intraocular pressure pattern in glaucomatous and nonglaucomatous patients. J Cataract Refract Surg 1996;22:607-11.

28. Contreras I, Noval S, Gonzalez Martin-Moro J, et al. [IOP spikes following contact transscleral diode laser cyclophotocoagulation] (In Spanish). Arch Soc Esp Oftalmol 2004;79:105-9.

29. Walland MJ. Diode laser cyclophotocoagulation: longer term follow up of a standardized treatment protocol. Clin Experiment Ophthalmol 2000;28:263-7.

30. Al-Torbak AA, Al-Shahwan S, Al-Jadaan I, et al. Endophthalmitis associated with the Ahmed glaucoma valve implant. Br J Ophthalmol 2005;89:454-8.

31. Krebs DB, Liebmann JM, Ritch $\mathrm{R}$, et al. Late infectious endophthalmitis from exposed glaucoma setons. Arch Ophthalmol 1992;110:174-5.

32. Melamed S, Cahane M, Gutman I, et al. Postoperative complications after Molteno implant surgery. Am J Ophthalmol 1991;111:319-22.

33. Centers for Disease Control (CDC). Update: Creutzfeldt-Jakob disease in a second patient who received a cadaveric dura mater graft. MMWR Morb Mortal Wkly Rep 1989;38:37-8, 43

34. King AJ, Azuara-Blanco A. Pericardial patch melting following glaucoma implant insertion. Eye 2001;15:236-7.

35. Lama PJ, Fechtner RD. Tube erosion following insertion of a glaucoma drainage device with a pericardial patch graft. Arch Ophthalmol 1999:117:1243-4. 


\section{Ahmed glaucoma valves in refractory glaucoma: a 7-year audit}

Peter K Wishart, Anshoo Choudhary and David Wong

Br J Ophthalmol 2010 94: 1174-1179 originally published online December 3, 2009

doi: 10.1136/bjo.2009.165357

Updated information and services can be found at:

http://bjo.bmj.com/content/94/9/1174.full.html

These include:

References This article cites 35 articles, 5 of which can be accessed free at: http://bjo.bmj.com/content/94/9/1174.full.html\#ref-list-1

Email alerting Receive free email alerts when new articles cite this article. Sign up in service the box at the top right corner of the online article.

Notes

To request permissions go to:

http://group.bmj.com/group/rights-licensing/permissions

To order reprints go to:

http://journals.bmj.com/cgi/reprintform

To subscribe to BMJ go to:

http://group.bmj.com/subscribe/ 